\title{
CONSIDERATIONS IN FORMULATION AND MANUFACTURING OF THICK FILM INKS
}

\author{
ADRIAN ROSE \\ Engelhard Industries Division, Engelhard Minerals \& Chemicals Corporation, East Newark, \\ New Jersey 07029
}

\begin{abstract}
This paper discusses considerations in formulation and manufacture of thick film inks. It deals with the components of thick film inks, their properties, functions, and manufacturing methods. The vehicle is defined and its components are discussed in terms of function, properties, and types. The various types of metals and their important properties are described and related to ink properties. Glass functions, types and properties are reviewed. Both vitreous and devitrifying glasses are examined. The usage of various types of oxides is discussed. Typical thick film inks are described. They include conductor, resistor, dielectric inks, and protective coatings. The types of components used are related to specific property requirements of each type of material. Ink manufacturing methods are described. Preparation of vehicle, metal powder, and glass frit is discussed. The process of incorporating these materials into an ink is detailed from initial mixing to final product. Testing, both in-process and final Q.C., is briefly discussed. The important considerations in both formulation and manufacturing are identified.
\end{abstract}

\section{INTRODUCTION}

Thick film engineers working in the design and fabrication of circuits usually have a reasonable understanding of the major ingredients in thick film inks. However, they often do not know in any detail the properties and purposes of many of the components going into such compositions. A knowledge of these components, their subtle and obvious interactions, functions, idiosyncracies, and the methods by which they are combined to produce a product can be of considerable value. This knowledge can contribute to the understanding of what inks can and cannot do, how they may best be processed, what each processing step may do, what can go wrong, and can assist in the solution of problems.

A thick film ink is a dispersion of very small particles of inorganic powders in a viscous liquid known as a vehicle. ${ }^{1}$ The inorganic powders may consist of one or more of the following classes of materials depending on the desired ink function and properties: metal, glass, oxides, and salts. In this paper, all of the components, their properties and functions, how they are used in various types of inks, as well as the manufacturing techniques used to produce thick film inks will be examined.

\section{INK FORMULATION}

Inks are usually applied by silk screen printing to ceramic substrates. They are then fired at high temperatures to give precise mechanical and electrical properties. Because of the necessity of printing extremely small circuits with good dimensional control in large numbers, the flow or rheological properties of the ink must be well characterized. The effect of these properties on screen printing must be known. These characteristics should not change appreciably even after the ink has been on the printer for hours during a production run. Such properties must be reproducible from batch to batch. Unlike the graphic arts, thick film printing requires a precise three dimensional deposition. Solids content must be constant from lot to lot. This must be achieved without varying rheology. Because all inks are fired at high temperatures, thermal characteristics must be known and controlled to allow smooth and complete organic burn-off and film maturation during firing. Finally, the desired physical, chemical, and electrical properties of the fired film must be achieved even when processing conditions deviate within reasonable limits. Each component has its contribution to these ends. 


\section{VEHICLE}

The vehicle usually consists of three main types of materials: an organic binder, a solvent, and a wetting agent. While inorganic powders are responsible for the properties of the fired film, the vehicle enables these powders to be applied properly to the substrate. For this reason the vehicle is vitally important although during firing the vehicle is completely decomposed or "burned-off" leaving no trace of it in the final film.

The binder is a resin or polymeric material. It serves two main functions: a) to impart proper rheology to the composition, b) to hold the inorganic powders together after the ink is printed and dried. Various materials are used as binders. Cellulosic polymers and terpene resins are two classes of materials commonly used. Special care is taken in selecting the binder to insure that its molecular weight, chemical composition, molecule polarity, and solubility will impart desired rheological properties to the ink. In addition the binder must burn-off during firing leaving no residue and should not impart stringiness or tack to the vehicle. The binder should also wet the powders involved.

The solvent should have a low vapor pressure at room temperature so that the ink will not dry or thicken by evaporation on the screen during a long printing run. It must have a relatively high vapor pressure at $100^{\circ}-150^{\circ} \mathrm{C}$ to facilitate rapid oven drying of the printed parts. High boiling solvents, such as the longer chain esters, half alcohol esters, and terpenes are frequently used. In addition to clean burn-off during firing, solvents should not possess objectionable odours, and should have low toxicity. The binder and solvent are usually chosen as a compatible pair.

The wetting agent allows the inorganic powder to be thoroughly wetted and dispersed in the vehicle. It also causes the ink to better wet the substrate thus facilitating printing. Since it frequently effects rheology the wetting agent is selected carefully from an almost endless list of commercially available surfactants.

\section{METALS}

Gold, platinum, palladium, iridium, ruthenium, rhodium, silver, copper, nickel, and aluminum, in fine particle size form either alone or in combination are used (see Figure 1). Combinations may be as alloys or in mixtures. The nature of the metal particles is extremely important. They must be selected carefully for two main reasons:

1) Thick films are heterophase composites in which the properties of the film are not only influenced by the

\begin{tabular}{|c|c|c|c|c|c|}
\hline $\begin{array}{l}\text { Product } \\
\text { Number }\end{array}$ & Composition & $\begin{array}{l}\text { Tap } \\
\text { Density } \\
\text { gm cc }\end{array}$ & $\begin{array}{l}\text { Surface } \\
\text { Area } \\
\mathrm{m} \text { gm }\end{array}$ & $\begin{array}{l}\text { Average } \\
\text { Particle } \\
\text { Size } \mu\end{array}$ & Form \\
\hline A 1570 & $\mathrm{Au}$ & 6.5 & $040070^{\circ}$ & 25 & Flake-Sphere \\
\hline 6408 & $P d$ & 0.9 & 1217 & 19 & Sphere \\
\hline A. 2270 & $P d$ & 1.1 & 1530 & 20 & Sphere \\
\hline A. 2382 & $\mathrm{Pd}$ & 1.5 & 5.56 .5 & 1.7 & Sphere \\
\hline A. 3565 & Pd & 1.0 & 3.0425 & 15 & Sphere \\
\hline A. 3491 & Pd & 1.0 & 2025 & 20 & Sphere \\
\hline 4 & $\mathbf{P t}$ & 1.1 & 1217 & 11 & Sphere \\
\hline A.2206 & Ag & 3.5 & 0508 & 40 & Sphere \\
\hline A. 3358 & $80 \mathrm{Ag} 20 \mathrm{Pd}$ & 2.2 & 3545 & 15 & $\begin{array}{l}\text { Sub Micron } \\
\text { Mixture }\end{array}$ \\
\hline A. 3142 & $65 \mathrm{Ag} 35 \mathrm{Pd}$ & 20 & 4265 & 15 & $\begin{array}{l}\text { Sub Micron } \\
\text { Mixture }\end{array}$ \\
\hline A 3498 & $40 \mathrm{Ag} 60 \mathrm{Pd}$ & 10 & 3545 & 15 & $\begin{array}{l}\text { Sut) Micron } \\
\text { Mixture }\end{array}$ \\
\hline A. 3381 & $30 \mathrm{Ag} 70 \mathrm{Pd}$ & 2.0 & 5060 & 15 & $\begin{array}{l}\text { Sub Micron } \\
\text { Mixture. }\end{array}$ \\
\hline A. 2979 & $20 \mathrm{Ag} / 80 \mathrm{Pd}$ & 20 & 4050 & 15 & $\begin{array}{l}\text { Sub) Muron } \\
\text { Mixture. }\end{array}$ \\
\hline A 2399 & $75 \mathrm{Au} 25 \mathrm{Pd}$ & 15 & 5070 & 17 & Allov \\
\hline A 2614 & 75 Au $25 \mathrm{Pd}$ & 18 & 2837 & 15 & Allov \\
\hline E-303E & $60 \mathrm{Au} 20 \mathrm{Pd} 20 \mathrm{Pt}$ & & 3049 & 15 & \\
\hline A. 2146 & $40 \mathrm{Au} 20 \mathrm{Pd} 40 \mathrm{Pt}$ & 2.0 & 7090 & 15 & Allor \\
\hline A 2207 & $70 \mathrm{Au} 20 \mathrm{Pd} 10 \mathrm{Pt}$ & 1.5 & 4060 & 15 & Allory \\
\hline A 2216 & $70 \wedge \mathrm{Au} 22.5 \mathrm{Pd} 75 \mathrm{Pt}$ & 15 & $4(1) 60$ & 15 & Allov \\
\hline A 3361 & Pdo & & 1520 & 15 & \\
\hline A. 2810 & $\mathrm{RuO}_{2}$ & & $36 b_{6} ;$ & & \\
\hline A 3366 & $\mathrm{RuO}_{2}$ & & 511 & & \\
\hline
\end{tabular}

FIGURE 1 Typical metal powders for thick film formulations.

bulk properties of the metals, but also are strongly influenced by their surface and other particulate properties. $^{2}$

2) The metals in some formulations form the major portion of the inorganic powders and strongly influence the rheological properties of the ink.

The most commonly measured properties of metal powders are surface area, particle size, tap density, and purity. Surface area is one of the most important powder properties. It is expressed in square meters of surface per gram of powder and measured by the amount of gas absorbed on the surface of a known weight of powder (see Figure 2). In general, finer particles have a greater surface area than coarser ones. Changes in surface area strongly influence viscosity and the amount of metal loading that can be achieved. A number of physical and chemical reactions are also influenced. Platinum group metals exhibit catalytic activity and can cause chemical changes in vehicles. Combustion of the film during the drying step can occur from a too high surface area or wrong vehicle choices. Capacitor internal electrode inks require very narrow ranges of surface area powders.

Particle size and particle size distribution affect both ink behavior and fired film properties. They are measured by a number of methods including the Coulter Counter and Micromerograph (see Figure 3). Printing, film density, presence of voids, film surface smoothness, film conductivity, and adhesion are all influenced by particle size. Sintering is greatly affected 


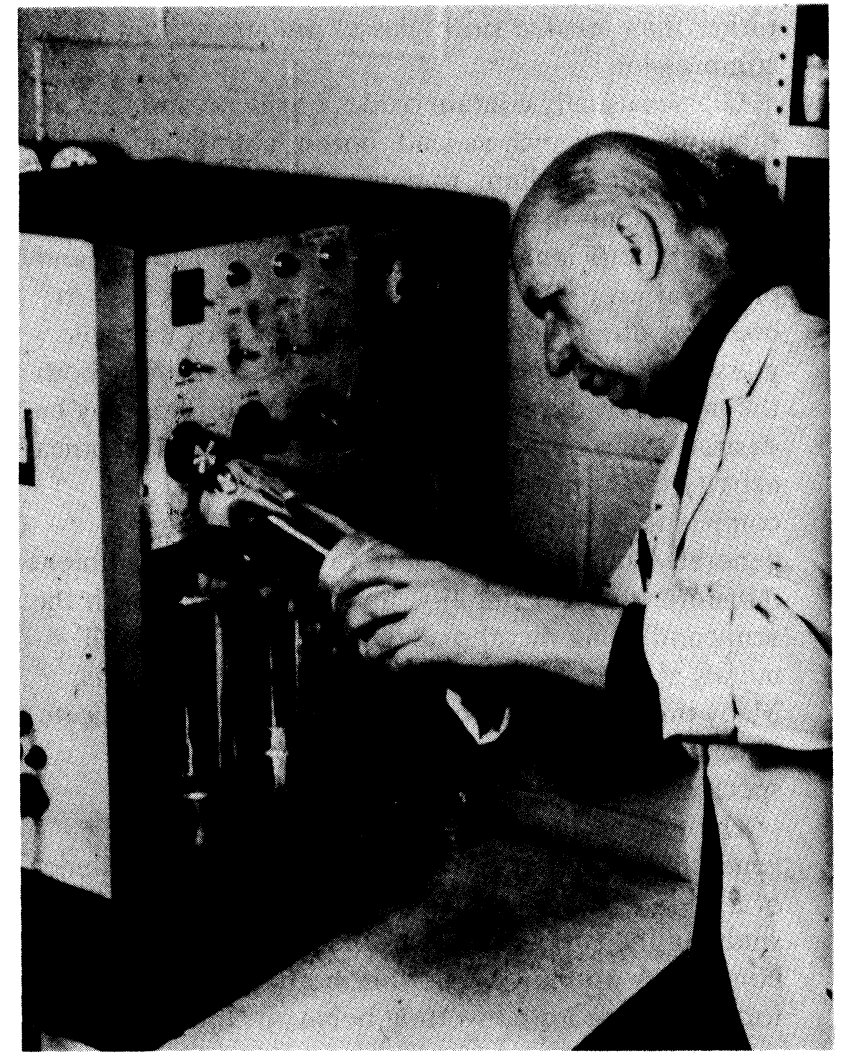

FIGURE 2 Surface area measurement

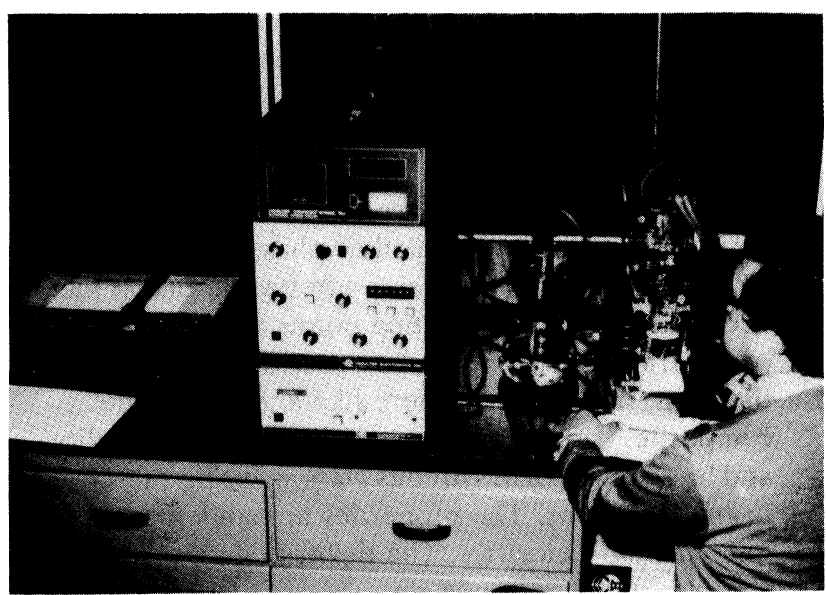

FIGURE 3 Particle size measuring equipment.

by both particle size and particle size distribution. ${ }^{3}$ Figure 4 shows particle size distribution of a typical powder.

It is desirable to maintain constant solids content from batch to batch for dimensional control. It is

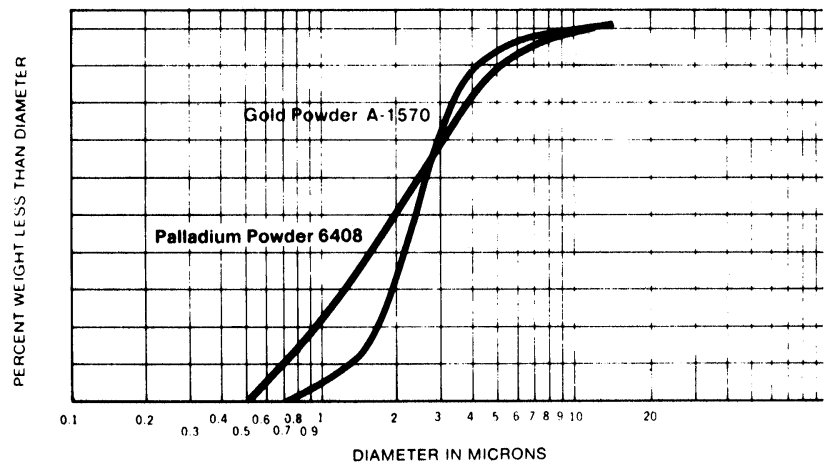

FIGURE 4 Typical particle size distribution curves.

important to control the precious metal percentage precisely. This is accomplished by using metal powders with the range of particle size distributions and surface areas held within very narrow limits. At Engelhard, precious metal content of inks is held within $\pm 0.1 \%$, from lot to lot.

Some formulators are interested in particle shape when specifying powder on flake or a mixture of the two. It should be noted that only extremely malleable metals, silver and gold, are likely to be used as flake.

It may be necessary to determine whether particles are regular or long, irregular and/or feathery, since the density of the fired film depends not only on size but on shape. The presence or absence of agglomerates which can be quite hard and difficult to break up is also of interest. Shape can best be determined by electron microscopy although optical microscopy can determine the presence of agglomerates (see Figures 5 and 6).

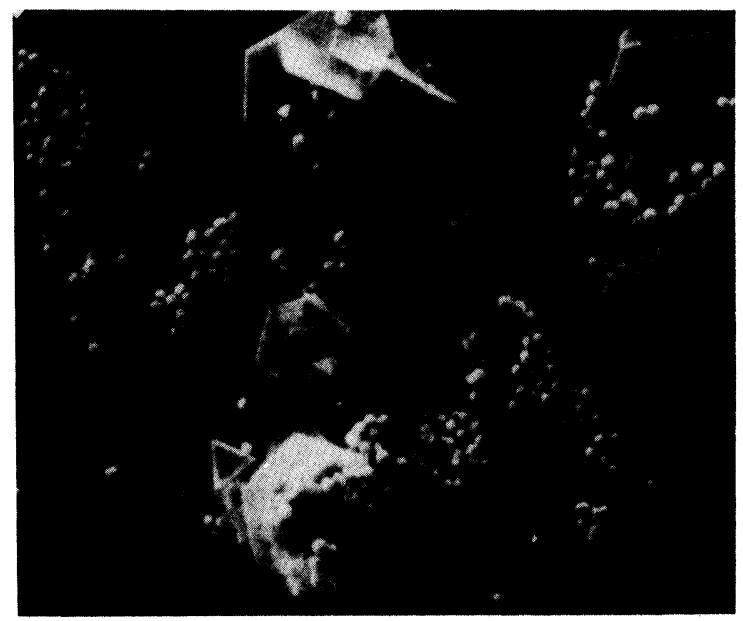

FIGURE 5 Gold powder A-1179 10,000 × 


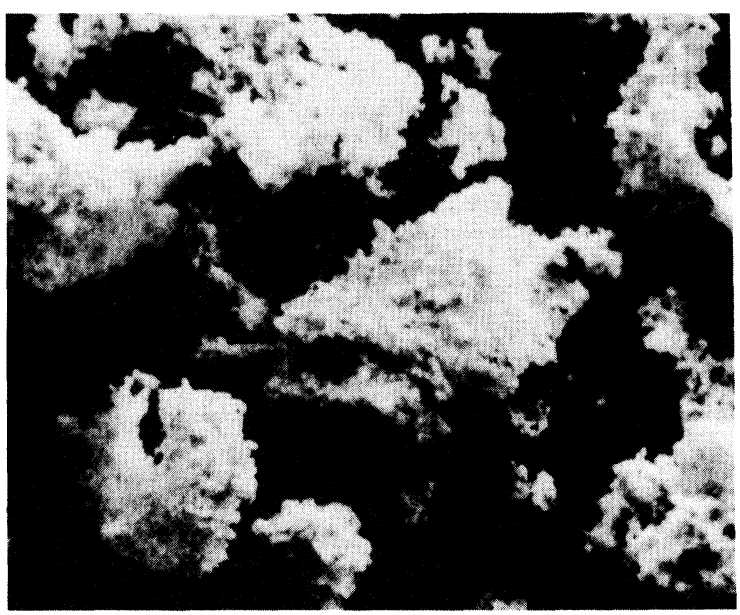

FIGURE 6 Palladium powder A-2270 $1000 \times$.

Tap density is also an important parameter. It is related to particle shape and size distribution. Tap density is sometimes used where more sophisticated particle measuring equipment is not available.

\section{GLASS AND GLASS FORMING OXIDES}

During firing the organic vehicle burns off. It is then necessary for some portion of the inorganic powder to undergo a physical or chemical change to develop film adhesion. This function is frequently performed by glass which flows and forms a composite with metal powders present while bonding to the substrate.

Glass may also be used as a diluent to modify the properties of another component in the system. In resistor inks, for example, the conductivity of metals and semiconducting oxides is reduced by dilution with glass to obtain a variety of sheet resistivities.

Glass is a viscous liquid, not a solid, and has no melting point. However, viscosity drops as temperature is increased. Various terms are used to describe the behavior of glass at elevated temperatures. Ideally, a glass should have enough flow over the firing temperature range of interest to develop adequate adhesion and a stable compact structure. It should not be so fluid as to flow out of the composite producing a porous or cracked film.

The thermal coefficient of expansion from the setting point of the glass (this is the temperature below which it can be considered rigid and corresponds to a viscosity of $10^{14}$ poises) down to the lowest temperature to which the circuit will be exposed should be close to that of the substrate. The glass should be in compression rather than tension since glasses are stronger in compression.

Glasses usually contain oxides of silicon and various other elements such as lead, boron, aluminum, zinc, cadmium, and sodium, to name a few. The selection of the ingredients in a glass is important since each affects thermal coefficient of expansion, chemical activity, and electrical properties. Some glasses may work well in one type of ink and poorly in another. For example, glasses with relatively high chemical activity wet both the metal powders and the substrate well. This may be desirable in a conductor formulation but such chemical activity might produce a rather unstable resistor composition. For resistor compositions glass is generally chosen for resistance to the effects of ambient moisture, thermal stability, and compatibility with the semiconducting metal oxides in the system. Alkali metals are generally avoided in glass compositions. Many thick film inks use glasses of the lead borosilicate type. These often contain other oxides to obtain specific properties.

The glasses chosen must wet the substrate and generally the metals in the system as well. The tendency of a glass to wet a surface may be determined by studying the surface energies of all the phase boundaries present. While this method may be useful for calculating initial wetting behavoir, the behavoir may change as the surfaces irreversibly alter during firing. ${ }^{4}$ For example, metals may dissolve in the glass changing its composition. Metal oxides often dissolve and change the surface of the metal. In practice glasses are often simply tested on a substrate by empirical spreading tests.

Both vitreous and devitrifying glasses are used. A vitreous glass retains its fluid structure during processing and subsequent cooling. A devitrifying glass develops one or more crystalline phases during heating. These phases usually develop after some fusion has occurred. Since their melting points are usually considerably higher than the processing temperature the glass, which is now more like a glass-ceramic composite, demonstrates more dimensional stability and less activity than vitreous glasses during subsequent firing operations. The properties are sometimes useful in crossover dielectrics. The devitrified glass is often stronger than a vitreous glass.

Various semiconducting oxides are used in thick film inks. These include ruthenium dioxide used in resistor compositions, and non-stoichiometric oxides of iron, nickel, and cobalt in thermistors.

Modifiers are frequently added to ink compositions to obtain specific properties. Bismuth compounds are used to increase solderability $\mathrm{Al}_{2} \mathrm{O}_{3}$ may be added to a 
glass in a dielectric formulation. When the glass starts to flow during firing it will dissolve the alumina rapidly increasing the melt viscosity and rendering the dielectric immobile and relatively nonreactive during subsequent firings. ${ }^{5}$

Sometimes a small quantity of an oxide which reacts with the substrate is used to obtain adhesion by chemical rather than mechanical means. Copper oxide, for example, reacts with alumina substrates at high firing temperatures to form a copper aluminate spinel. The fired film is more adhesive than a similar film in which only glass is used to adhere to the substrate. ${ }^{6}$

Occasionally, salts are used in place of oxides to incorporate the necessary elements in a convenient form. These may by either inorganic such as bismuth subcarbonate, or metallo-organic such as copper ocotate.

\section{TYPICAL INKS}

\subsection{Conductor}

These contain a large amount of metal and a small amount of glass, reactive oxides or mixtures of these, and possibly modifiers or salts. The metal glass ratio is important. Too much glass will give poor solderability and wire bonding and not enough will cause poor adhesion. Superior films result when glass composition is carefully optimized to give the best combination of properties.

The vehicle must wet the powders well. This is a problem with some base metal inks which fire in neutral or reducing atmospheres since binders and wetting agents which impart the needed wetting action are usually difficult to burn off. Others which give easier burn off have poor wetting action. For this reason many early base metal inks had poor rheology.

The fine line definition required of many conductive inks imposes stringent rheology requirements and much research is directed toward the formulation of newer and better vehicle systems.

\subsection{Resistor}

These contain semiconducting oxides and sometimes noble metals as well as glass. Resistivity is varied by varying the amount and type of semiconducting oxides and the amount of glass present. TCR is also affected by this and frequently small amounts of "dopants" (elements or compounds that have a strong effect on TCR) are introduced. Since each member of a series of resistor inks has a different composition to obtain the desired resistivities and TCRs, it is possible to blend two inks to achieve intermediate resistor values and have the resulting resistivity or TCR outside the range of the blending members. Such nonlinear blending characteristics are avoided if the formulator makes the composition of adjacent members of a series as similar as possible.

\subsection{Dielectric}

These inks are of two main types, capacitor and multilayer. The capacitor formulations contain powders found in ceramic capacitor bodies, barium titanate, various Curie Point modifiers, and a small amount of glass. Since even small amounts of glass lower the dielectric constant appreciably, the minimum amount necessary is used in high " $\mathrm{K}$ " inks.

There are two types of multilayer dielectrics. One, called a glass-ceramic or crystallizing dielectric, contains a devitrifying glass. The second, known as a filled glass type, contains a combination of glasses and a high melting oxide such as alumina. The glass-ceramic type must be formulated so that crystallization proceeds rapidly at the firing temperature of interest. However, too rapid or too much crystallization can result in excessive porosity. With insufficient crystallization the dielectric may be too "glassy". This results in top conductor "swimming" and conductor dielectric reaction. Filled-glass dielectrics offer greater flexibility in formulation, since the number of suitable glasses far exceeds the number of compositions that may be induced to crystallize at the temperature range of interest. The formulation must be balanced so that it is neither too glassy nor too porous. The expansion of the glass should match the substrate. Metallic diffusion rates in the dielectric should be as low as possible. Silver displays high diffusion rates in most glasses.

Multilayer dielectrics frequently are dyed. Organic dyes which burn off in firing are used for identification and ease of inspection of the unfired film since a light colored dielectric on a white substrate is difficult to see. These are referred to as fugitive dyes. Permanent dyes may be incorporated in the glass to retain color after firing. These are selected carefully since some glass colorants can effect dissipation factor.

\subsection{Protective coatings}

Resistor overglazes are the most commonly used protective coating for hybrid circuitry. These consist of a glass which matches the thermal expansion coefficient of the resistor, and which does not adversely affect it. Because the coating overlaps conductor and bare 
substrate area, each with different expansion coefficients, some stresses in the overglaze are inevitable. Particle size distribution is optimized and the solids content is adjusted so that a relatively thin film is deposited. This minimizes cracking. To avoid resistor shifts during overglaze firing low temperature firing glasses are used. Frequently a green colorant is added to absorb YAG laser energy during resistor trimming.

\section{INK MANUFACTURE}

Methods of manufacture are similar for most inks. Typical methods are as follows.

\subsection{Vehicle}

The solvent and wetting agents are mixed and while the liquid is stirred the binder is added. The process may be augmented by additional heating to obtain rapid solution and keep the viscosity low. When solution is complete the vehicle is allowed to cool. During the operation the temperature is kept below the point at which the components might begin to decompose.

\subsection{Metal powder}

Most powder used in thick film inks is produced by chemical precipitation under carefully controlled conditions although some mechanical processing is used (see Figures 7 and 8).

\subsection{Glass}

The glass forming oxides are mixed in a V-cone blender, placed in ceramic or platinum and fused at temperatures of normally between $1000^{\circ} \mathrm{C}$ and $1500^{\circ} \mathrm{C}$, then poured into cold water. This instantly quenches the molten glass shattering it into a coarse powder. The process is known as fritting, producing a glass powder known as a frit. The term "frit" if applied to every glass powder used in thick film inks is incorrect. The powder is then ball milled and dried.

\subsection{Mixing and dispersing}

In order to combine the powders and vehicle to form a smooth homogeneous ink, powder must be mixed with vehicle then milled to disperse the powder.

A rough mix is first made. The powder is mixed in a planetary mixer which acts similarly to a household mixmaster. This wets the powder with the vehicle and

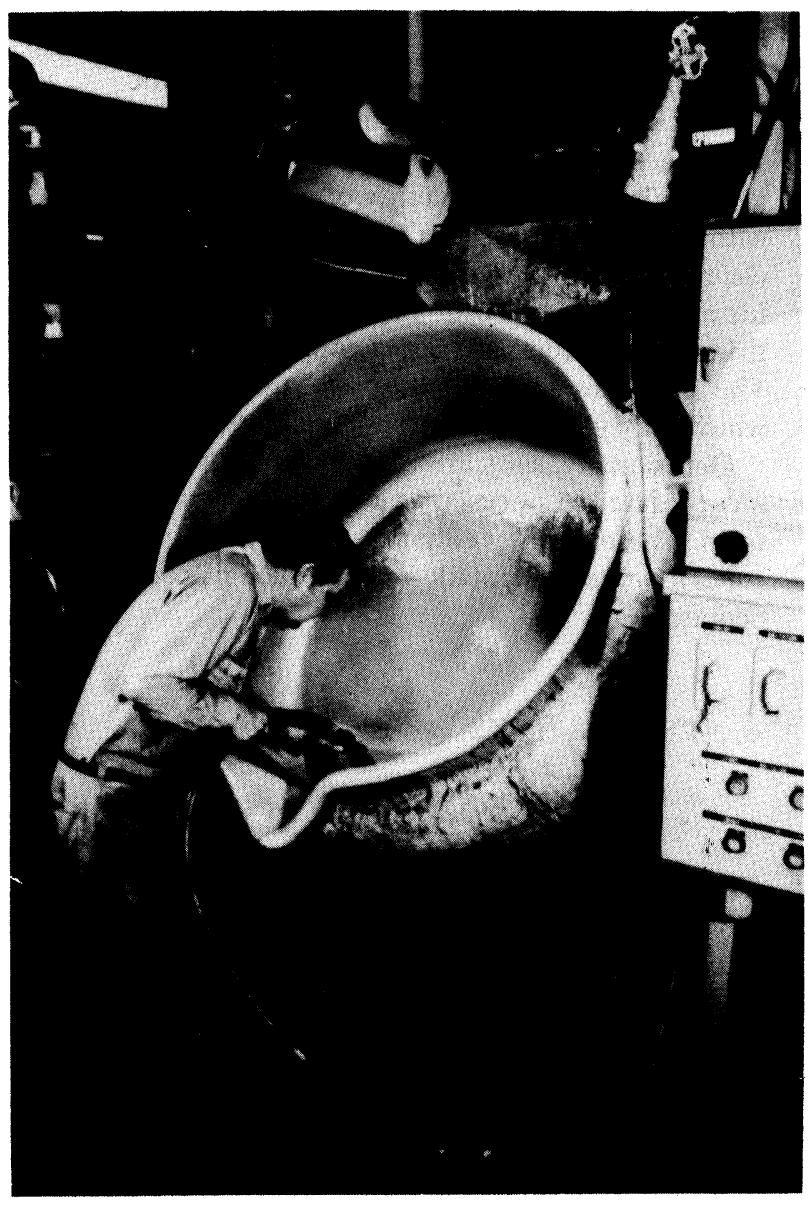

FIGURE 7 Gold powder production.

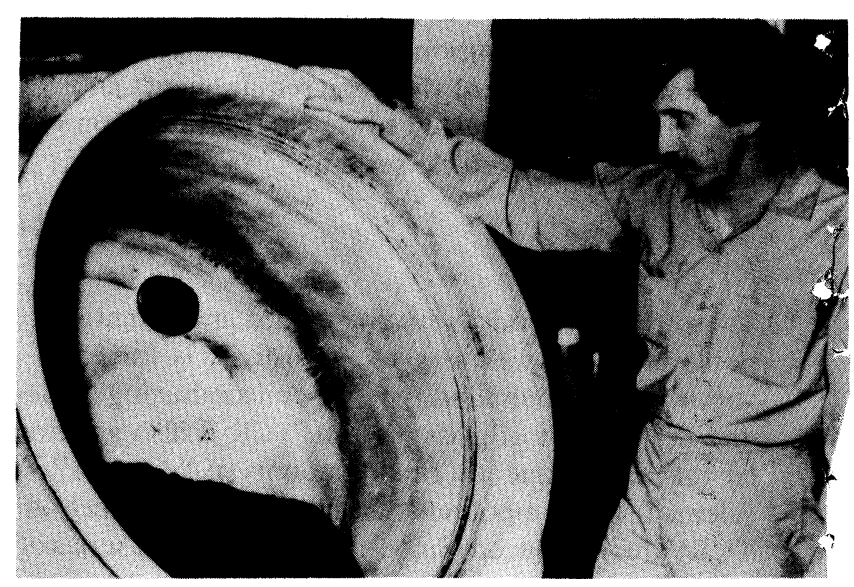

FIGURE 8 Platinum powder production. 


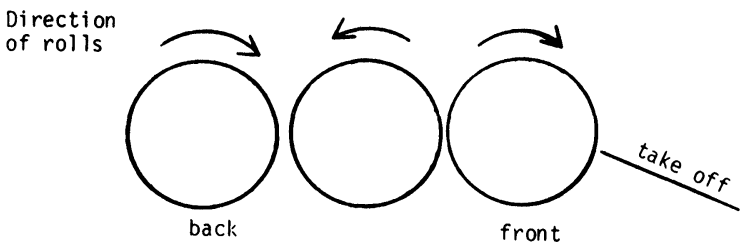

FIGURE 9 Roll action with three roll mill.

breaks up the larger agglomerates. The process is continued until all the powder is wet and large lumps are broken. It is important to emphasize that if this is not accomplished prior to roll milling the mill may be damaged. Malleable metal insufficiently mixed has a tendency to form large flakes or sheets during milling.

The mixture is next transferred to a three roll mill (see Figure 9). This is comprised of three in-line rolls separated by small adjustable gaps which are rotated in different directions at different speeds relative to each other. The rear roll is the slowest. The middle roll is faster and the front roll the fastest. A takeoff blade scrapes the ink off the front roll. From here it goes down a chute and is collected.

The tremendous shearing action further breaks down powder agglomerates and serves to completely wet the powder. The ink is cycled repeatedly through the mill. The roll gaps are gradually decreased until the desired amount of dispersion is obtained. Great care must be taken during the processing of the inks to avoid flaking the metal particles. Formulations such as dielectrics and overglazes must be milled carefully to avoid contamination of metal from the rolls. At this point the ink, now a smooth homogeneous material, is finished. Storage, testing, and packaging follows.

\subsection{Testing}

Thick film ink manufacturers measure physical and electrical properties of interest to the user. The manufacturer also tests for a number of other properties important for quality control, but which are not of interest to every user.

Fineness of grind is a measure of both particle size and how well the ink dispersed in milling. It is used as both an in-process test and a Q.C. test. Ink is doctorbladed across a metal block in which a calibrated groove with decreasing depth has been machined. The resultant film has scratches in it which begin at the point where a particle larger than the depth of the groove is picked up by the blade. The number of scratches of different sizes is indicative of the size distribution of particles in the ink.

Rheology is one of the most important properties controlled by the manufacturer to assure that the ink will perform properly in the users application. This is measured most often with both the Brookfield viscometer and those of the cone-plated type such as Ferranti-Shirley. Information can range from simple process control data to sophisticated data which may be correlated with screen printing behavior.

Product stability is an important consideration in the formulation of thick film inks. Stability at room temperature, and at high and low temperatures likely to be encountered during shipment, is measured whenever a new system is formulated.

\section{CONCLUSION}

Formulation of thick film inks involves careful control of raw materials as well as selection of materials to optimize these complex heterophase products for their intended purpose. Manufacturing is accomplished by straightforward techniques, requiring only care in procedure, and suitable and sufficient testing upon completion.

\section{REFERENCES}

1. M. L. Topfer, Thick Film Microelectronics, Van Nostrand Reinhold Co., N.Y., p. 43 (1971).

2. C. Schaeffer, and Sergent, "The Effect of Particle Size Distribution on the Electrical Properties of $\mathrm{RuO}_{2}$ Thick Film Resistors", Proceedings, International Microelectronics Conference (ISHM, US), 1977.

3. S. S. Cole, "The Sintering Mechanism is a Silver Palladium Film", Proceedings, International Microelectronics Conference (ISHM, US), 1972.

4. W. D. Kingery, H. K. Bowen, and D. R. Uhlmann, Introduction to Ceramics, John Wiley and Sons, N.Y., p. 211 (1960).

5. S. S. Cole and G. Wellfair, "High Temperature Viscosity Control in Multilayer Glasses - a New Concept", Proceedings, International Microelectronics Conference (ISHM, US), 1974.

6. P. Says, "A Discussion of Molecular Bonding Conductive Films", presented at IEEE Region 3 Conference, Orlando, Florida, 9/30/74. 

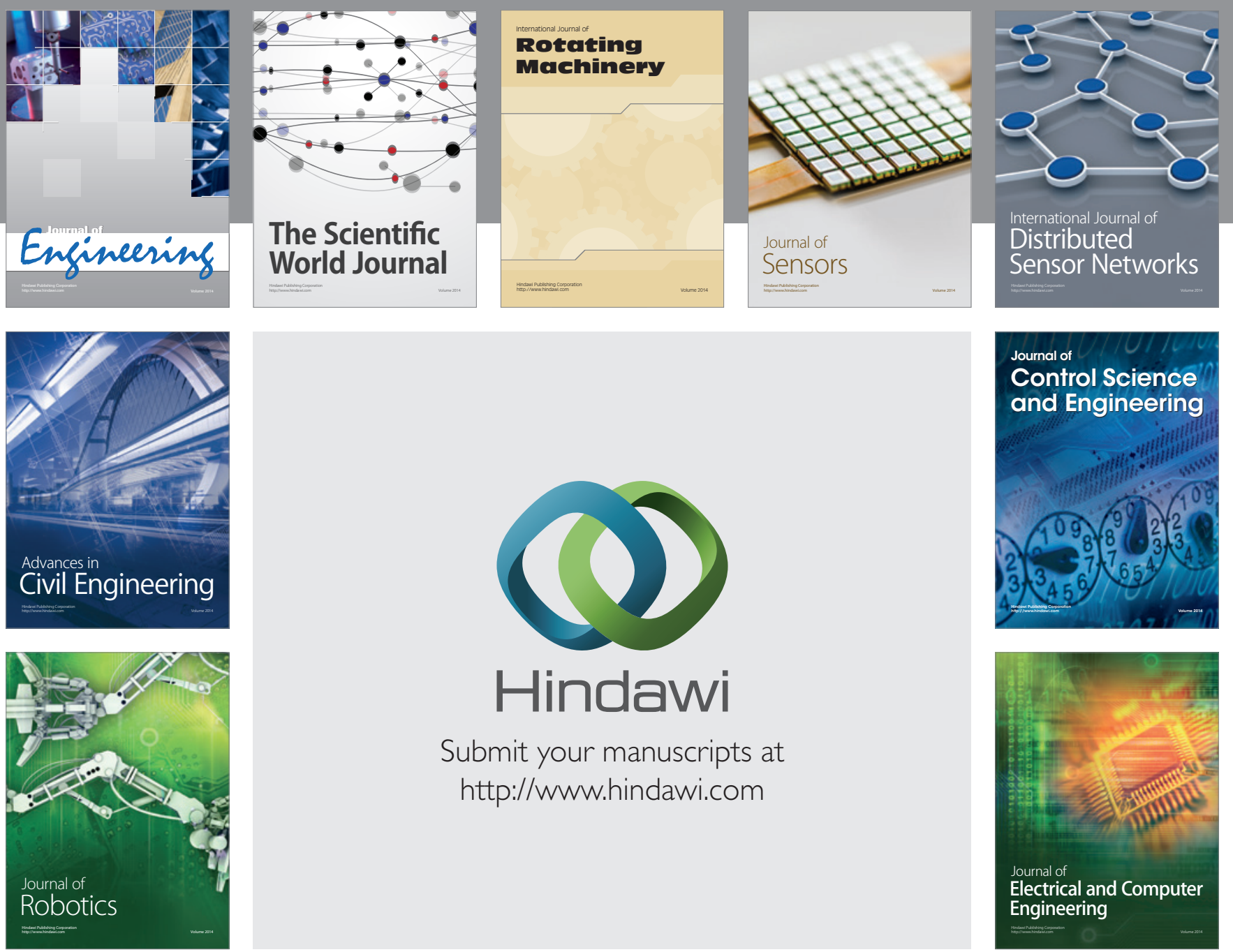

Submit your manuscripts at

http://www.hindawi.com
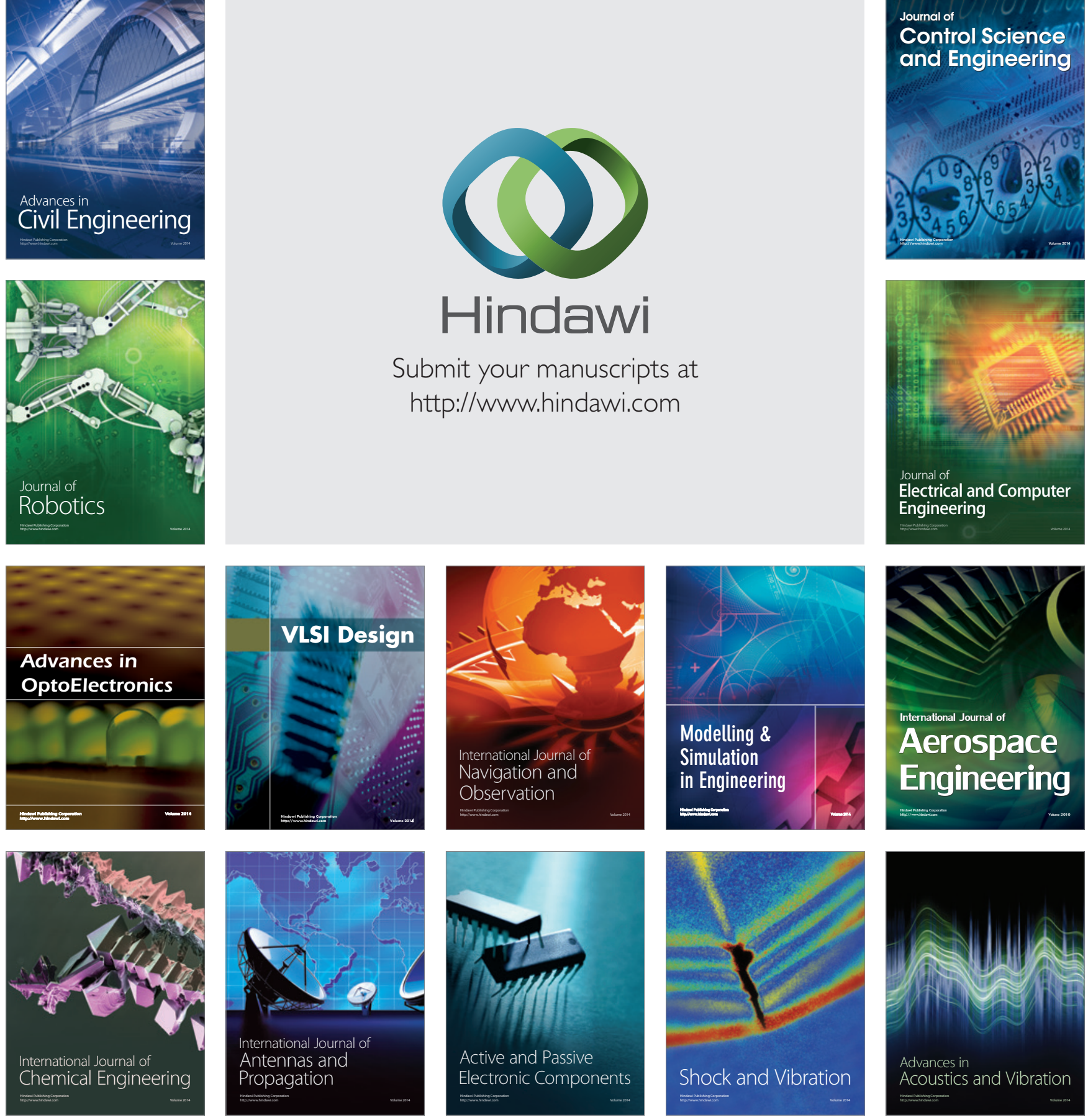